\title{
Numerical comparative study of five currently used implants for high tibial osteotomy: realistic loading including muscle forces versus simplified experimental loading
}

Arnaud Diffo Kaze ${ }^{1,2,4^{*}}$ (1) Stefan Maas ${ }^{1,4}$, Slawomir Kedziora ${ }^{1}$, James Belsey ${ }^{5}$, Alexander Haupert ${ }^{6}$, Claude Wolf ${ }^{1}$, Alexander Hoffmann ${ }^{2,3,4}$ and Dietrich Pape $2,3,4$

\begin{abstract}
Background: Many different fixation devices are used to maintain the correction angle after medial open wedge high tibial osteotomy (MOWHTO). Each device must provide at least sufficient mechanical stability to avoid loss of correction and unwanted fracture of the contralateral cortex until the bone heals. In the present study, the mechanical stability of following different implants was compared: the TomoFix small stature (sm), the TomoFix standard (std), the Contour Lock, the iBalance and the second generation PEEKPower. Simplified loading, usually consisting of a vertical load applied to the tibia plateau, is used for experimental testing of fixation devices and also in numerical studies. Therefore, this study additionally compared this simplified experimental loading with a more realistic loading that includes the muscle forces.
\end{abstract}

Method: Two types of finite element models, according to the considered loading, were created. The first type numerically simulated the static tests of MOWHTO implants performed in a previous experimental biomechanical study, by applying a vertical compressive load perpendicularly to the plateau of the osteotomized tibia. The second type included muscle forces in finite element models of the lower limb with osteotomized tibiae and simulated the stance phase of normal gait. Section forces in the models were determined and compared. Stresses in the implants and contralateral cortex, and micromovements of the osteotomy wedge, were calculated.

Results: For both loading types, the stresses in the implants were lower than the threshold values defined by the material strength. The stresses in the lateral cortex were smaller than the ultimate tensile strength of the cortical bone. The implants iBalance and Contour Lock allowed the smallest micromovements of the wedge, while the PEEKPower allowed the highest. There was a correlation between the micromovements of the wedge, obtained for the simplified loading of the tibia, and the more realistic loading of the lower limb at $15 \%$ of the gait cycle (Pearson's value $r=0.982$ ).

\footnotetext{
* Correspondence: adiffokaze@yahoo.fr

${ }^{1}$ Faculty of Science, Technology and Communication, University of Luxembourg, 6, rue R. Coudenhove-Kalergi, L-1359 Luxembourg, Luxembourg

2Department of Orthopedic Surgery, Centre Hospitalier de Luxembourg,

L-1460 Luxembourg, Luxembourg

Full list of author information is available at the end of the article
} 


\begin{abstract}
(Continued from previous page)
Conclusions: An axial compressive load applied perpendicularly to the tibia plateau, with a magnitude equal to the first peak value of the knee joint contact forces, corresponds quite well to a realistic loading of the tibia during the stance phase of normal gait (at 15\% of the gait cycle and a knee flexion of about 22 degrees). However, this magnitude of the knee joint contact forces overloads the tibia compared to more realistic calculations, where the muscle forces are considered. The iBalance and Contour Lock implants provide higher rigidity to the bone-implant constructs compared to the TomoFix and the PEEKPower plates.
\end{abstract}

Keywords: Finite element, Musculoskeletal model, Lower limb, Knee joint, Muscle forces, Stance phase, Medial open wedge HTO, iBalance, Contour lock, PEEKPower, TomoFix, Section forces

\section{Background}

Medial Open Wedge High Tibial Osteotomy (MOWHTO) is a well-established surgery technique used to treat medial compartment osteoarthritis with varus malalignment in young and active patients (Pape et al. 2004). There are many different implants used during medial open wedge high tibial osteotomy (MOWHTO) for correcting varus deformity of the knee associated with medial compartment osteoarthritis. Numerous biomechanical studies have been carried out in order to investigate the mechanical stability of these different fixation systems. Biomechanical studies in orthopaedics can be divided in two groups: experimental and numerical studies. The experimental studies use specimen, which consist of physical prototypes of the bones and cadaveric bones. The numerical studies use three-dimensional (3D) geometries of the bones in finite element models. Finite element models are computer aided designed models that are based on finite element methods. In experimental studies, the loads are applied to the specimen by means of testing machines and the deformations of the specimens are captured by means of sensors. In finite element models, numerical simulations are performed, the loads are applied to the body of interest and the body response to those loads is numerically calculated. These bodies can be bones, soft tissues, implants or screws etc. The response to the applied external loads are deformations, strains and stresses. The biomechanical studies that were carried out in order to investigate the mechanical stability were generally performed experimentally (Spahn and Wittig 2002; Stoffel et al. 2004; Zhim et al. 2005; Agneskirchner et al. 2006; Maas et al. 2013; Watanabe et al. 2014; Diffo Kaze et al. 2015) or by numerical computation, for instance, finite element (FE) analyses (Izaham et al. 2012; Luo et al. 2013; Pauchard et al. 2015; Luo et al. 2015). For the experimental studies, simplified loading of the specimens was applied. Static or dynamic loading conditions consisting generally of axial compression loading (Spahn and Wittig 2002; Stoffel et al. 2004; Zhim et al. 2005; Spahn et al. 2007; Agneskirchner et al. 2006; Maas et al. 2013), or more rarely, of torsional loading (Stoffel et al. 2004) of the specimens are considered. The same applies to numerical studies using FE methods, where the loading conditions were also reduced to axial forces that were applied to the tibia head (Blecha et al. 2005; Izaham et al. 2012; Luo et al. 2013; Pauchard et al. 2015; Luo et al. 2015). In addition to gait loads, Blecha et al. (Blecha et al. 2005) considered femorotibial contact loads due to muscular tonus that compressed the wedge. With the exception of the study by Blecha et al., all the other previously mentioned studies did not consider muscle forces. Experimentally determined knee contact forces are predominantly vertical, though the components in the transverse plane are not zero (Heinlein et al. 2009; Kutzner et al. 2010). Hence, they should be somehow considered. Furthermore, experimental testing procedures should consider realistic loading (Brinkman et al. 2014). However, it remains difficult to realise life-like test conditions in an experimental setting.

The main aim of the present study was to compare five implants currently used for MOWHTO on one side, and to highlight the influence of muscle forces on the other side. For this purpose, two different loading conditions were compared: (1) a simplified loading consisting in applying a vertical compressive force to the tibia plateau, and (2) a more realistic loading considering the muscle forces during the stance phase of normal gait. Furthermore, the study also aimed to match the two loading types, in order to validate the experimental setting, which was used for previous comparative biomechanical experimental studies conducted by Diffo Kaze et al. (Diffo Kaze et al. 2015). Therefore, the simplified and the more complex loading were applied to FE models.

The following five plates were compared (Fig. 1): The Contour Lock, the PEEKPower and the iBalance implants of Arthrex (Arthrex, Munich, Germany), and the TomoFix standard (std) and small stature (sm) plates of Synthes (Depuy Synthes GmbH, Oberdorf, Switzerland). The study compared the effects of the previously mentioned implants in terms of stresses and wedge motions. The hypothesis was that the applied simplified experimental loading corresponds approximately to a realistic loading of the knee joint during the stance phase of gait. 

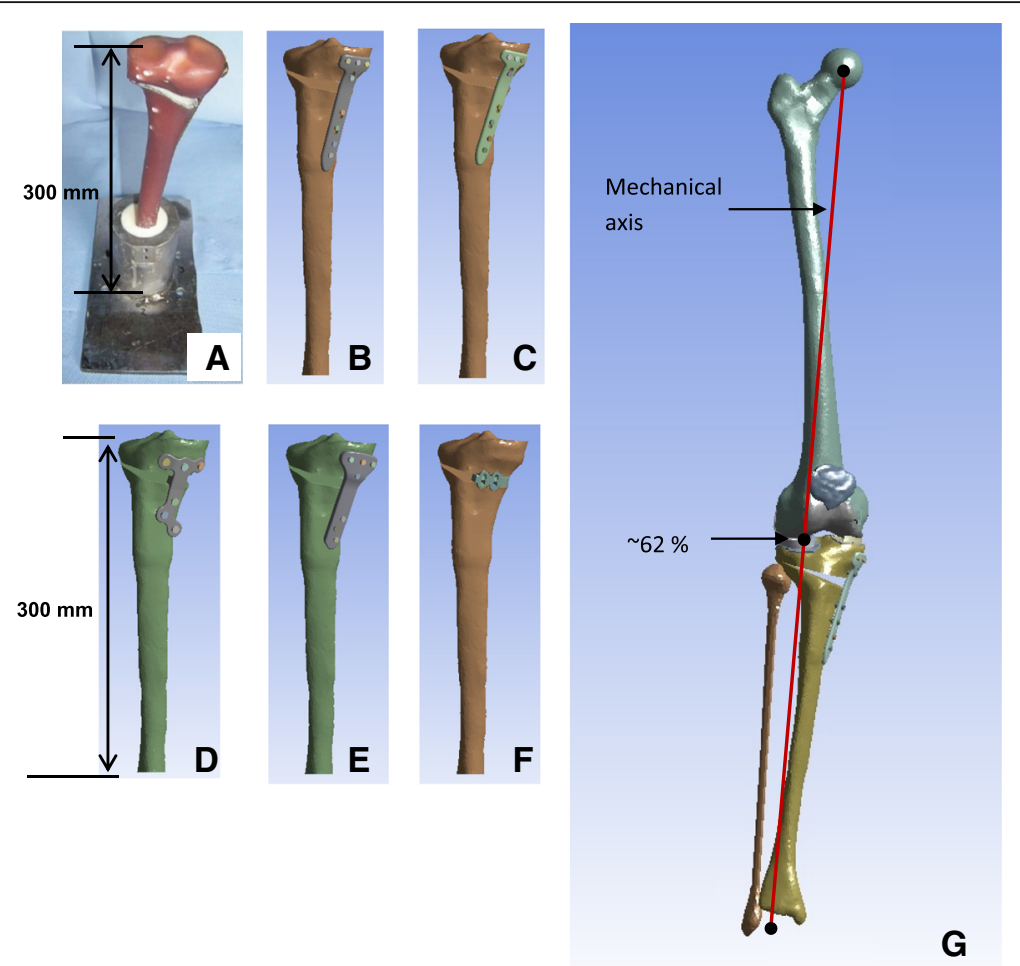

Fig. 1 3D Geometries of models: a Photo of a tested specimen of the experimental study (Diffo Kaze et al. 2015). 3D geometries of the specimen (b) TomoFix Std, (c) TomoFix sm, (d) Contour Lock, (e) PEEKPower, (f) iBalance. (g) 3D geometries of the lower limb model including the osteotomized tibia with the TomoFix std plate. The mechanical axis passed through the Fujisawa point laterally at $62 \%$ of the tibia plateau width

\section{Methods}

\section{General study design}

The simplified loading was applied to FE models simulating the previously performed experimental studies by Diffo Kaze et al. (Diffo Kaze et al. 2015). The more realistic loading was applied to FE models of the lower limb, which were created to achieve the aims of the present study. The results of both FE model types were analysed and compared.

\section{Bone and plate models}

3D geometries of the bones were generated from the mesh of a previous study. This mesh was developed using the state-of-art procedure of 3D geometry acquisition, which was based on segmentation of medical image data and was previously described by Beilas et al. (Beillas et al. 2001). The data for the procedure were collected using medical computer tomography (CT) scanning and magnetic resonance imaging (MRI) on a subject close to a 50th percentile male (Beillas et al. 2001). The FE software package HyperWorks-Radioss (Altair Engineering, Inc., Antony, France) was used to generate the geometries of the bones from the existing mesh and to manually create the geometries of the soft tissues based on anatomy books. The geometry data files were then imported into the Design Modeler of the Release 16.2 of
ANSYS Workbench FE software package (Ansys, Inc., Canonsburg, Pennsylvania, U.S.A), which was used to perform the FE analyses. The bones were constituted only of cortical bone and no medullary canal was modelled for the sake of simplicity. The osteotomized tibia was created by: (1) performing an upward mediolateral cut, starting on the medial side at $35 \mathrm{~mm}$ distal to the tibia plateau and ending in the contralateral cortical bone at $20 \mathrm{~mm}$ distal to the tibia plateau, about $6 \mathrm{~mm}$ from the lateral cortex; and (2) by creating an opening of $10^{\circ}$ that corresponded to the average value of the correction angle currently performed.

The geometries of the plates and screws (Fig. 1) were created using the software MSC Marc (MSC Software Paris, Paris, France). The screws were modelled as cylindrical with diameters corresponding to the nominal diameters of the device screws following the recommendations of the manufacturers. All parts of the models were meshed with 10 node solid tetrahedral elements.

\section{Geometries of the models of the biomechanical experimental study}

The osteotomized tibia was cut $300 \mathrm{~mm}$ distal from the tibia plateau as indicated in our previously performed biomechanical experimental studies (Maas et al. 2013; Diffo Kaze et al. 2015). The cut of the tibia was such that 
the tibia plateau was horizontal (Fig. 1). Except the fact that uniplanar osteotomies were modelled, all the numerical models were created in conformity with the respective techniques of the fixation systems.

\section{Geometries of the models of the lower limb}

The mechanical axis of the lower limb model passed through the Fujisawa point located laterally at $62 \%$ of the tibia plateau width of the osteotomized tibia (Fig. 1g). The lower limb model was constituted of the femur, the tibia, the fibula and the patella. The soft tissues within the knee were the articular cartilages of the tibia and femoral heads, the articular cartilage of the patella, and the menisci and the patellar tendon, which was modelled with three springs. The other knee joint ligaments were not considered. This was justified by the fact that the interface surfaces within the knee joint were modelled as bonded to keep the model linear.

\section{Material parameters}

The constitutive laws for the cortical bones, the soft tissues and the implants were assumed to be linear elastic, homogeneous and isotropic. Young's modulus of wet embalmed cortical bone of the tibia from younger (41.5 years old) and older (72 years old) men are 18,900 MPa and 16,200 MPa respectively (Evans 1976). Hence a Young's modulus of $17,000 \mathrm{MPa}$ for the cortical bone was considered for the bones. The biphasic nature of the soft tissues was not taken into account. Furthermore, considering the short loading time during normal walking compared to the viscoelastic time constant of cartilage, the articular cartilage can be modelled as isotropic linear elastic (Donahue et al. 2002; Kiapour et al. 2014). Young's modulus was $15 \mathrm{MPa}$ for the articular cartilage (Donahue et al. 2002; Hao et al. 2007; Kiapour et al. 2014). Young's modulus of the menisci is higher in the circumferential direction $(120 \mathrm{MPa})$ compared in radial and transversal directions (20 MPa) (Farrokhi et al. 2011). Hence a Young's modulus of $120 \mathrm{MPa}$ was considered to model the material behaviour of the menisci as linear isotropic. In the literature, when the soft tissues were considered as homogenous linear isotropic materials, Poisson's ratio ranged from 0.3 to 0.49 for the menisci, and from 0.4 to 0.475 for the articular cartilage (Beillas et al. 2001; Peña et al. 2005; Hao et al. 2007; Farrokhi et al. 2011). In the present study, Poisson's ratios were 0.45 for menisci and articular cartilage, and 0.3 for bone.

The patellar tendon was modelled with three springs and the stiffness was determined by using the following formula

$$
k=\frac{E \cdot A}{L},
$$

where $\mathrm{E}$ was the Young's modulus, A the surface of the transversal section and $\mathrm{L}$ the length of the patellar tendon. The following values were used: $\mathrm{E}=900 \mathrm{MPa}$ (Haraldsson et al. 2005; DeFrate et al. 2007) and $\mathrm{A}=$ $160 \mathrm{~mm}^{2}$ (Hansen et al. 2006; DeFrate et al. 2007). For the length $\mathrm{L}$ of the tendon, a mean value of $5 \mathrm{~mm}$ was defined according to the geometry. Hence the stiffness coefficient of the patellar tendon was $\mathrm{k}=2880 \mathrm{~N} / \mathrm{mm}$, which corresponded to $\mathrm{k}_{\text {spring }}=960 \mathrm{~N} / \mathrm{mm}$ for each of the three springs.

The material parameters that were used for the different fixation devices are summarized in Table 1. For the titanium plates, namely the Contour Lock and the TomoFix plates, material properties of the grade II titanium were used in the present study (Thielen 2009; Fischer et al. 2011). The iBalance implant is made of polyetheretherketone (PEEK) and the ultimate tensile strength of the unfilled PEEK ranges between $92 \mathrm{MPa}$ and $100 \mathrm{MPa}$ (MakeItFrom.com 2015). Its other mechanical properties were retrieved from different literature (Kohn and Ducheyne 2005; Garcia-Gonzalez et al. 2015). The PEEKPower plate is made of carbon reinforced PEEK. Its material properties, which were used in the present study, were taken from Fischer et al. (Fischer et al. 2011), except for the fatigue limit and the tensile yield strength. Based on published data of 30\% carbon reinforced PEEK 450G (Victrex Ltd 2015), the tensile stress-strain curves of PEEK typically do not exhibit a yield point and its fatigue limit was set at $160 \mathrm{MPa}$. The flexural yield strength of 30\% carbon reinforced PEEK was used instead of its tensile yield strength. The flexural yield strength of $30 \%$ carbon reinforced PEEK was $177.5 \mathrm{MPa}$ (Advanced Industrial 2015). Stainless steel was considered for the screws made of steel. The fatigue limit of stainless steel was approximated with $0.4 \mathrm{xRm}$.

Table 1 Material parameters of the fixation devices. They were all retrieved from the literature

\begin{tabular}{lccccc}
\hline Material & $\begin{array}{c}\text { Young's modulus } \\
(\mathrm{MPa})\end{array}$ & $\begin{array}{c}\text { Poisson's } \\
\text { ratio } u\end{array}$ & $\begin{array}{c}\text { Ultimate tensile } \\
\text { strength } R_{m}(\mathrm{MPa})\end{array}$ & $\begin{array}{c}\text { Yield strength } \\
R_{e}(\mathrm{MPa})\end{array}$ & $\begin{array}{c}\text { Fatigue limit } \\
\sigma_{D}(\mathrm{MPa})\end{array}$ \\
\hline Titanium & 110,000 & 0.3 & 500 & 250 & 200 \\
30\% carbon reinforced PEEK & 13,000 & 0.3 & 210 & 177.5 & 92 \\
PEEK & 3600 & 0.38 & $92-100$ & 460 & 70 \\
Stainless steel (316 L) & 210,000 & 0.3 & 480 & 170 & $0.4 \times R_{m}=192$ \\
\hline
\end{tabular}




\section{Loading, boundary conditions and analyses}

Each of the surfaces' fractions, which were in contact at the interfaces bone-cartilage, menisci-cartilage, femoral cartilage-patellar cartilage, fixation device-screws, fixation device-bone and bone-screw, were bonded in order to keep the different models linear and reduce complexity. Static analyses were performed. The stresses in the implants and in the contralateral cortical bone, as well as the micromovements of the osteotomized tibia wedge, were determined and analysed. A cross section of the contralateral cortex and a path (B1B2) on that cross section were chosen. The stress distribution on this cross section and on this path was determined. The cross section started at the tip of the wedge and ended at the external margin (Fig. 2-b). A suitable amount of micromovement between two fractured bony segments is said to promote callus formation and callus massage, thus helping the fracture healing process (Claes et al. 1997, 1998; Claes and Heigele 1999; Yamaji et al. 2001; Klein et al. 2003). The micromovements were assessed by the length variation of three very weak springs (Stiffness: $10^{-3} \mathrm{~N} / \mathrm{m}$ ) linking the outermost distal and proximal borders of the wedge on the medial side (Fig. 2-e). Influence of the muscle forces was determined by comparing
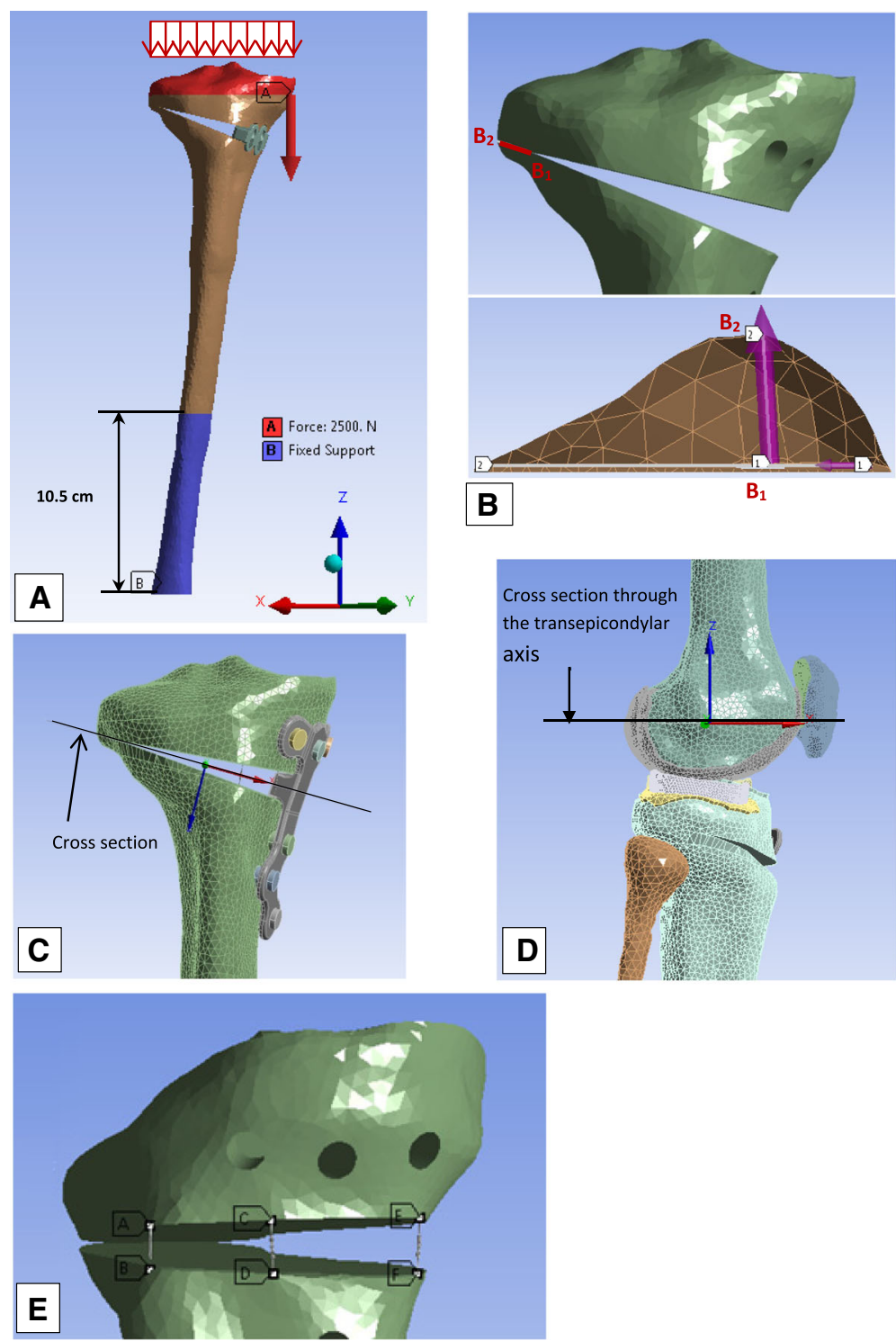

Fig. 2 Loading, boundary conditions and analyses: a Loading and boundary conditions of the simplified loading models. b Cross section of the contralateral cortex and path to check the stresses in the contralateral cortex; B1 and B2 were the starting point and the ending point of the path B1B2 that was chosen and on which the stress distribution was determined. c Cross section where section forces and moments were determined in order to highlight the influence of muscle forces. $\mathbf{d}$ Cross section passing through the transepicondylar axis that was defined in order to calculate the section forces in the knee joint. $\mathbf{e}$ The three weak springs (ab, $\mathbf{c d}$ and $\mathbf{e f}$ ) that were used to quantify the micromovements of the wedge 
the section forces on cross sections (Fig. 2-c and d) of the models for the two different loading types.

\section{Loading and boundary conditions for the simulation of the} stance phase of normal gait including the muscle forces Inertia effects are negligible in comparison to muscle forces during normal walking and hence were not considered in the present study. A more detailed description of the modelling methods of the present finite element models of the lower limb was published in a previous study (Diffo Kaze et al. 2017). The muscle forces acting in the lower limb during normal gait were calculated by means of a validated musculoskeletal rigid body (MRB) model (Manders et al. 2008; Thielen 2009; Asfour and Eltoukhy 2011) This MRB model, namely the Gaitfullbody model, is available in the model repository of the musculoskeletal modelling software AnyBody version 6 (AnyBody Technology 2014). The knee joint in the MRB was modelled as a revolute joint that was located in the middle of the transepicondylar axis. Hence, section forces in the cross section of the femoral head of the FE models passing through the transepicondylar axis (Fig. 2-d) were determined and compared to the knee joint forces, which were calculated by means of the MRB model. In order to simulate the stance phase, three positions of the stance phase were selected (Fig. 3) based on the knee joint forces that were calculated using the MRB model. The selected positions represented three different loading configurations that corresponded to the first peak (positions 1: $\sim 15 \%$ gait cycle and $22^{\circ}$ knee flexion), a local minimum between the two peaks (positions 2: $~ 30 \%$ gait cycle and $13^{\circ}$ knee flexion) and the second peak of the knee joint force (positions 3: 50\% gait cycle and $14^{\circ}$ knee flexion). The foot was not modelled, and a segment was used to model the foot sole and to locate the centre of pressure (COP), to which the ground reaction forces (GRF) were applied. The experimentally measured knee contact forces by Bergmann et al. (Bergmann 2008) were comparable to the knee joint forces of the used MRB model (Diffo Kaze et al. 2017). Hence, the muscle forces calculated by using the MRB model (Fig. 4) and the GRF were assumed to be valid. These data were then exported from AnyBody and were applied to the finite element models of the lower limb with the osteotomized tibia and the different implants (Fig. 1-g). The femur was attached to the ground with three very stiff springs (Stiffness: $10^{9} \mathrm{~N} / \mathrm{m}$ ), oriented in all three spatial directions, in order to constrain the translational degrees of freedom (DOF) of the centre of the femoral head. Three weak stabilisation springs (Stiffness: $1 \mathrm{~N} / \mathrm{mm}$ ), which were oriented in the three spatial directions, were attached at the distal basis of the tibia in order to avoid numerical instability of the models. The muscle forces were applied as distributed load over their respective origin and insertion areas, which were reproduced on the bone geometry surfaces, according to their anatomical locations. Tibia and fibula were bonded at their common interface.

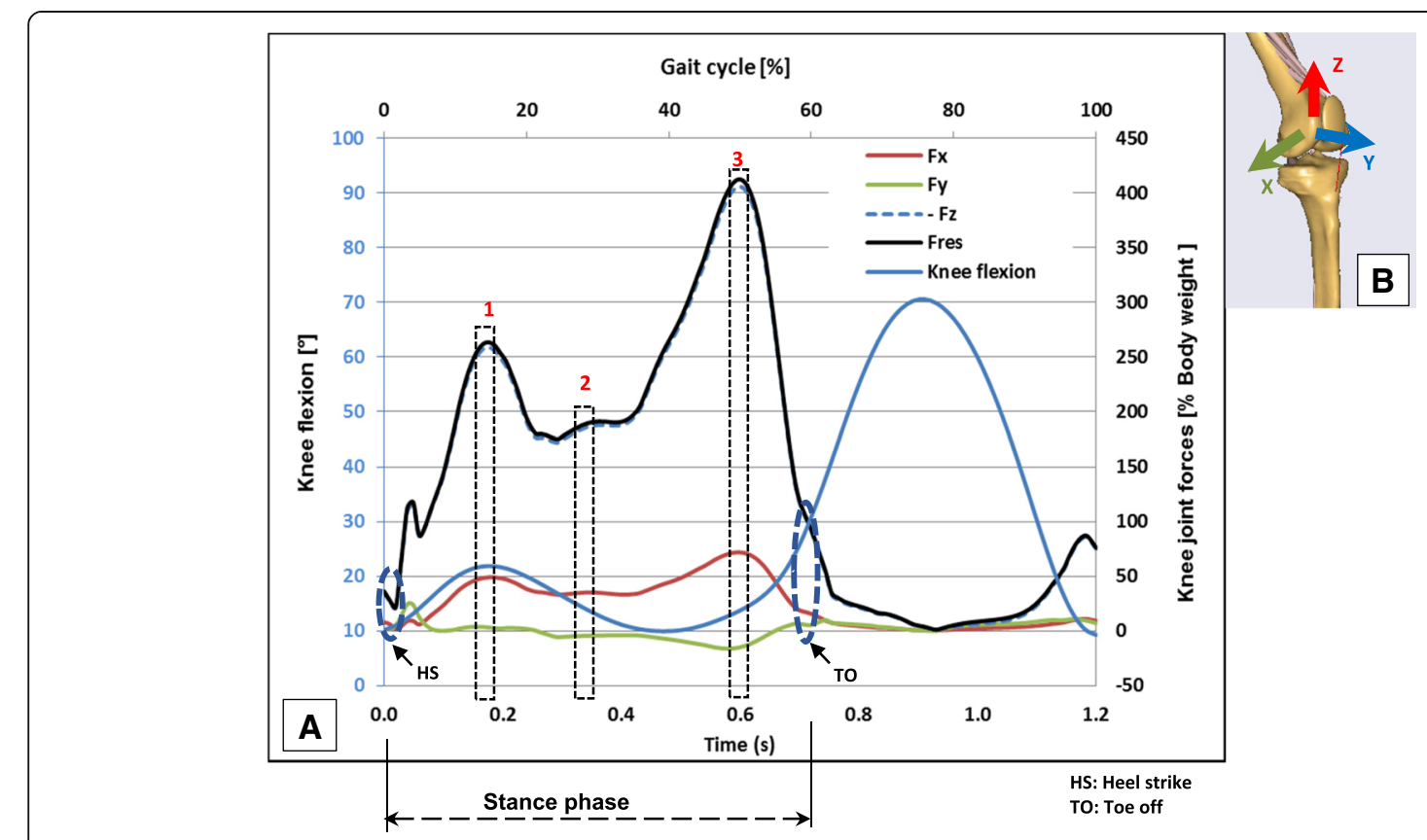

Fig. 3 The three analysed positions: a Components of the knee joint forces and knee joint flexion angle over the complete gait cycle. b Coordinate system used to define the calculated knee joint forces 


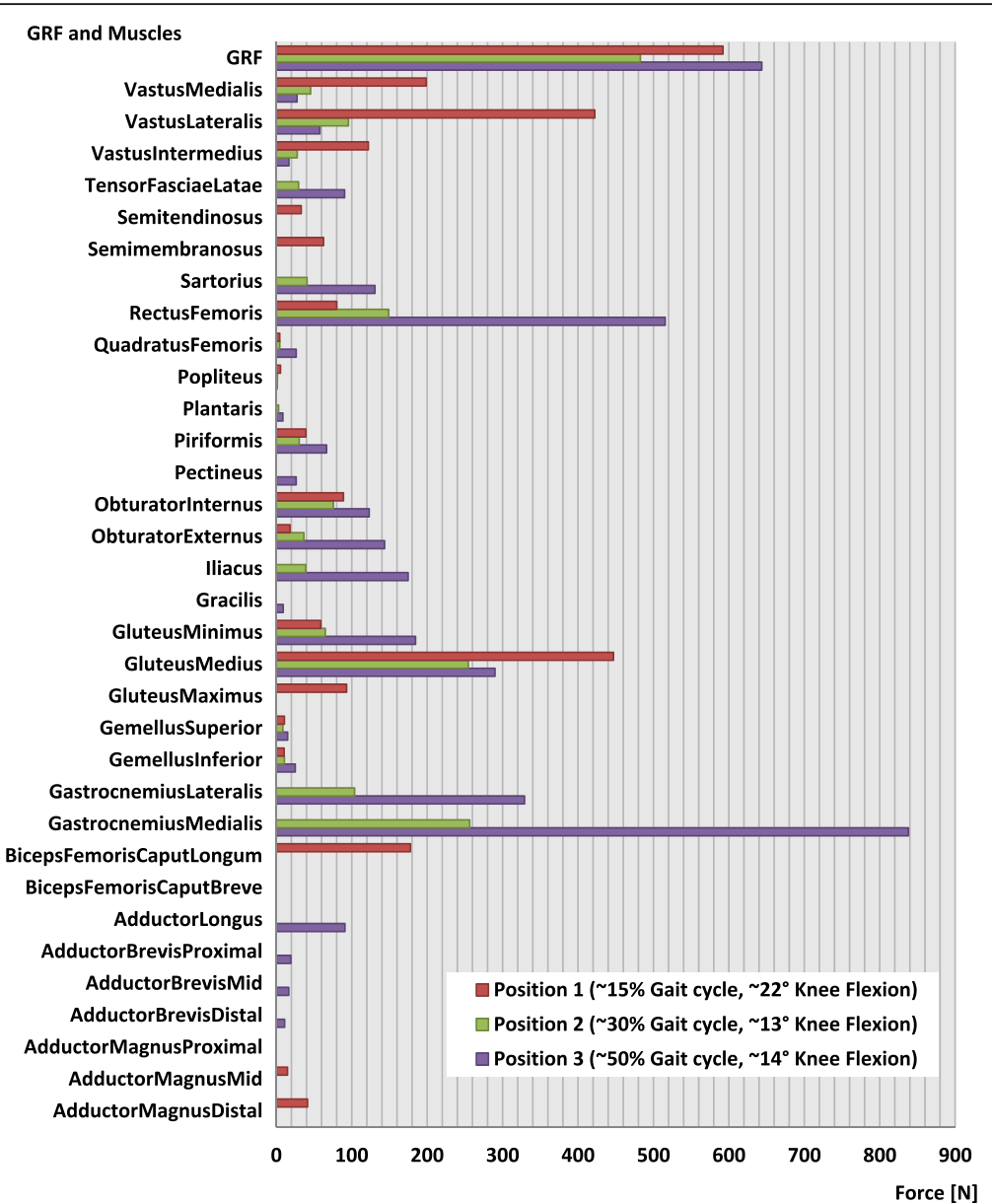

Fig. 4 Magnitudes of the muscle forces at the three selected positions: The set of the active muscles is different from one position to another

\section{Loading and boundary conditions for the simulation of the} experiments

The kinematics and kinetics data of a subject with a mass of $62 \mathrm{~kg}$ were used for the MRB model. The calculated maximal axial compressive load on the knee joint was $410 \%$ body weight (BW). For a person with a BW of 608.22 N, 410\% BW corresponds to $2500 \mathrm{~N}$, which was applied to the tibia head of the specimen, while the distal end was fixed (Fig. 2-a).

\section{Results}

Comparison of the loadings

The section forces and moments in the cross section following the wedge as shown in Fig. 2-c are given in Table 2. The forces and the moments were given in the local coordinate system located at the centroid of the cross section. The section forces, due to the muscles, were smaller than those resulting from the applied vertical load of $2500 \mathrm{~N}$, which considered as being a

Table 2 Comparison of the section forces and moments in the cross section shown in Fig. 2-C. The forces and the moments were given in the local coordinate system located at the centroid of the cross section. Fx, Fy, Fz were the components of the Force; Mx, My, Mz were the components of the Moment. Fres and Mres were the resulting of the force and of the moment respectively

\begin{tabular}{|c|c|c|c|c|c|c|c|c|c|}
\hline \multirow[t]{3}{*}{ Loading variations } & & \multicolumn{8}{|c|}{ Mean values of the section forces } \\
\hline & & \multicolumn{4}{|c|}{ Force $[\mathrm{N}]$} & \multicolumn{4}{|c|}{ Moment [N.m] } \\
\hline & & Fx & Fy & $\mathrm{Fz}$ & Fres & $M x$ & My & $\mathrm{Mz}$ & Mres \\
\hline Simplified loading & & 797 & -20 & 2365 & 2496 & -17 & -23 & 6 & 28 \\
\hline \multirow[t]{3}{*}{ Muscle actions } & Position 1 & 274 & -7 & 1220 & 1251 & -11 & 1 & 14 & 18 \\
\hline & Position 2 & 198 & 32 & 792 & 817 & -4 & -12 & 10 & 16 \\
\hline & Position 3 & 358 & 20 & 1762 & 1798 & -2 & -19 & 12 & 23 \\
\hline
\end{tabular}


Table 3 Comparison of the knee joint force in the MRB model with the section forces in the cross section passing through the transepicondylar axis of the femur (Fig. 2-d). The forces were given in the coordinate system of Fig. 3-b. Fx, Fy, Fz were the components of the Force; Mx, My, Mz were the components of the Moment. Fres and Mres were the resulting of the force and of the moment respectively

\begin{tabular}{|c|c|c|c|c|c|}
\hline \multirow[t]{2}{*}{$\begin{array}{l}\text { Positions } \\
\text { simulated }\end{array}$} & \multicolumn{4}{|c|}{$\begin{array}{l}\text { Mean values of the components of the section forces in the cross } \\
\text { section passing through the transepicondylar axis of the femur (Fig. 2-d) }\end{array}$} & \multirow{2}{*}{$\begin{array}{l}\text { Resultant of the knee joint } \\
\text { force from the MRB model } \\
\text { Fres }[\mathrm{N}]\end{array}$} \\
\hline & $\mathrm{Fx}[\mathrm{N}]$ & $\mathrm{Fy}[\mathrm{N}]$ & $\mathrm{Fz}[\mathrm{N}]$ & Fres[N] & \\
\hline Position 1 & -7 & 1790 & 71 & 1791 & 1650 \\
\hline Position 2 & 609 & 978 & 198 & 1169 & 1100 \\
\hline Position 3 & 1284 & 2275 & 180 & 2618 & 2500 \\
\hline
\end{tabular}

simplified loading. The resultant moments were of the same order of magnitude. There were no linear correlations between the loading types regarding the components of the section forces and moments. The resultant of the section force in the case of the simplified loading $(2496 \mathrm{~N})$ was approximately double the resultant of the section force $(1251 \mathrm{~N})$ in the case of muscle forces acting on the lower limb in position 1; and, both section forces were oriented distally and posteriorly.

Table 3 gives the components of the section forces in the section passing through the transepicondylar axis of the femur in the FE models including muscle forces and the knee joint forces of the MRB model. The resultants of these section forces were comparable to those of the knee

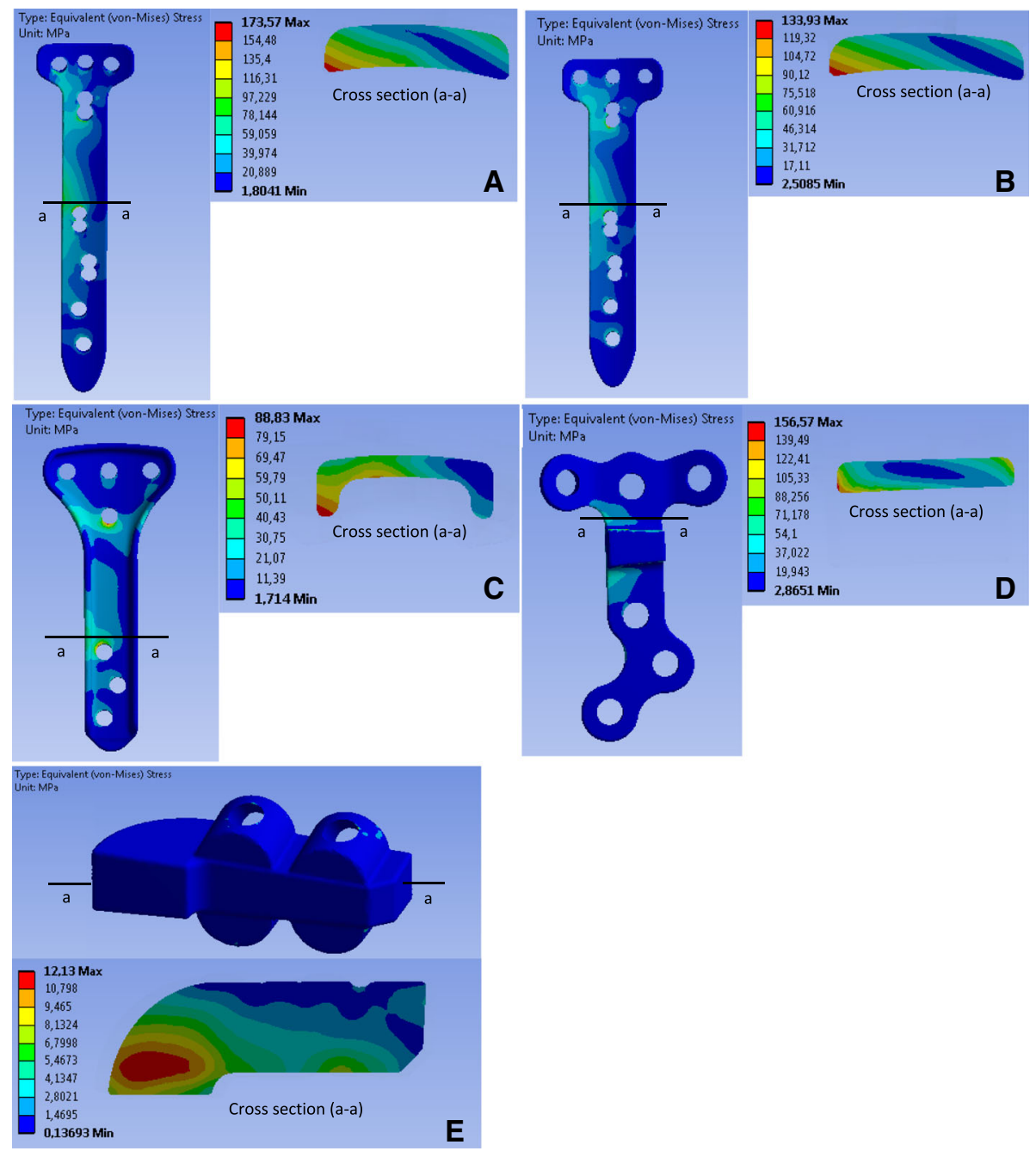

Fig. 5 Equivalent stress (von-Mises) in the implants after the simplified loading of the tibia: The letters $\mathbf{a}, \mathbf{b}, \mathbf{c}, \mathbf{d}$ and $\mathbf{e}$ indicates the TomoFix sm, the TomoFix std., the PEEKPower, the Contour Lock and the iBalance implants 
joint forces of the MRB model. The components of the forces were referred to the coordinate system of Fig. 3-b. For the lower limb in position 1, the section force was almost vertical as in the case of the simplified experimental loading. The magnitudes of the section forces in the femoral head were higher than those in the tibia wedge. This was due to the action of the muscles that had their insertions above the cross section of the wedge.

\section{Stress analysis of the implants}

A cross section (a-a) was defined in the implant where the equivalent von-Mises stresses were maximal. The stress distribution of this cross section was given for the different implants. Figure 5 shows the equivalent von-Mises stress in the implants after a static compressive load was applied to the tibia plateau, while Fig. 6,
Fig. 7 and Fig. 8 show the equivalent von-Mises stress after the lower limb was subjected to the muscle forces.

\section{Case of the simplified loading consisting in applying a}

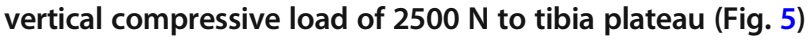
The maximal von-Mises equivalent stress was located, for the PEEKPower and the two TomoFix plates, in the region situated on the right margin just above the distal holes. The right side of the implants corresponded to the posterior region of the tibia. For the Contour Lock plate, the highly stressed region was located at the plate corner on the right side above the spacer. The stress distribution of the above mentioned plates highlighted a bending for which compressive stresses were higher than tensile stresses. For the iBalance, the highly stressed volume was in the middle on the right side.
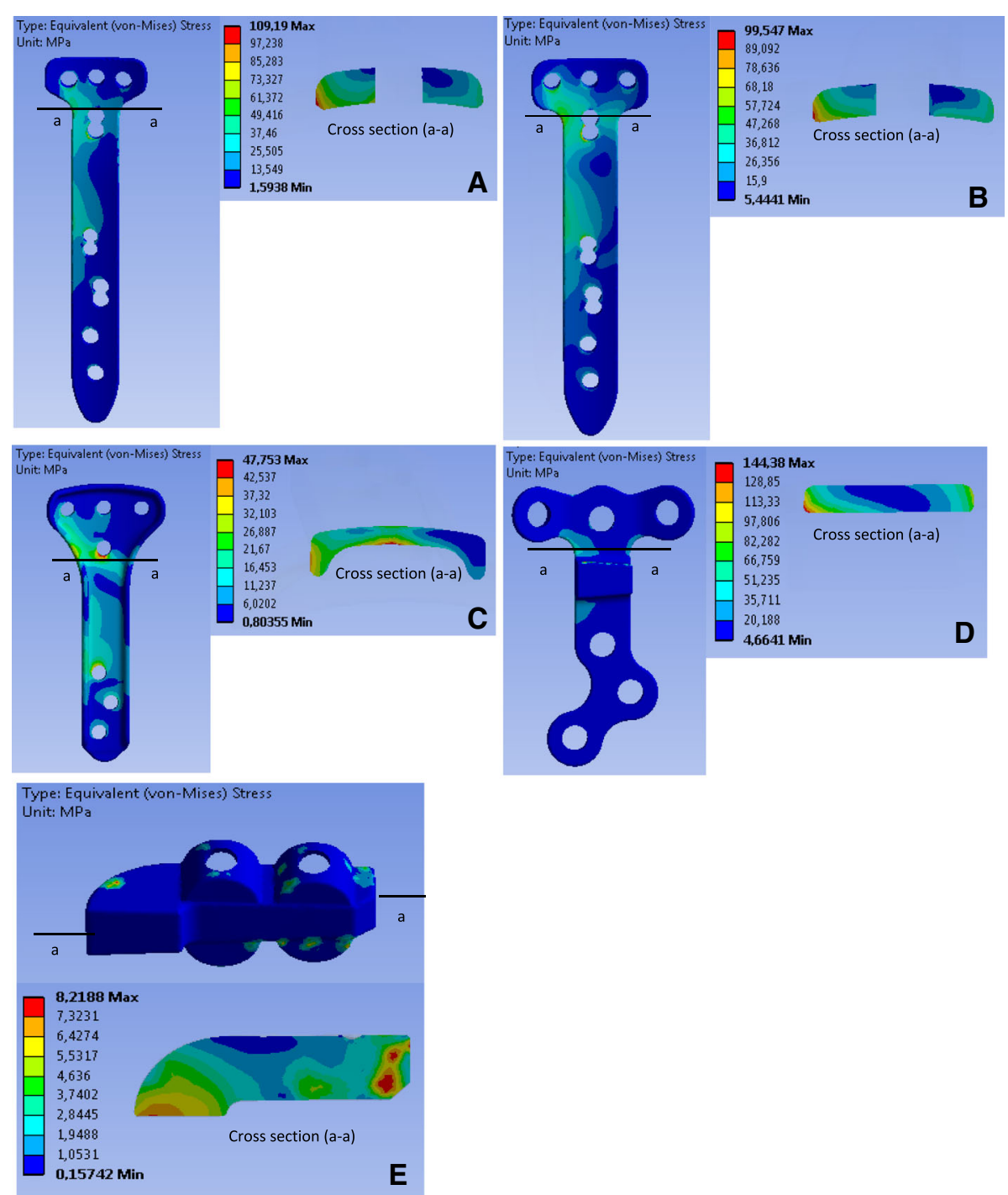

Fig. 6 Equivalent stress (von-Mises) in the implants in position 1: The letters $\mathbf{a}, \mathbf{b}, \mathbf{c}, \mathbf{d}$ and $\mathbf{e}$ indicate the TomoFix sm, the TomoFix std., the PEEK Power, the Contour Lock and the iBalance implants 


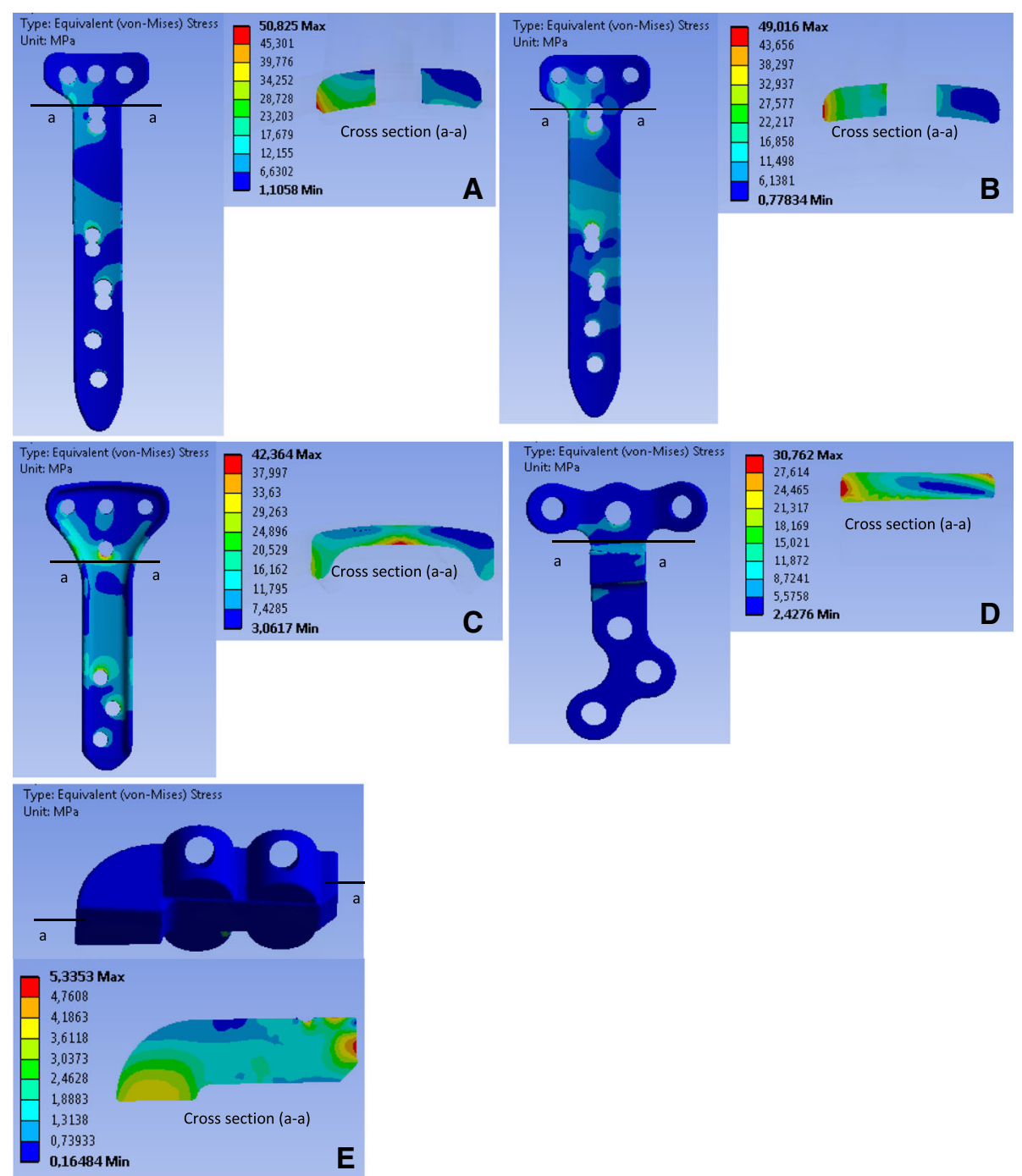

Fig. 7 Equivalent stress (von-Mises) in the implants in position 2: The letters $\mathbf{a}, \mathbf{b}, \mathbf{c}, \mathbf{d}$ and $\mathbf{e}$ indicate the TomoFix sm, the TomoFix std., the PEEK Power, the Contour Lock and the iBalance implants

Case of the more realistic loading including the muscle actions (Fig. 6, Fig. 7 and Fig. 8)

Position 1 - Fig. 6: The maximal von-Mises equivalent stress was located at the plate corner on the right side for all the plates except for the iBalance implant. Additionally, for the PEEKPower, the margin of the middle region below the proximal hole, above the wedge, was highly stressed. For the iBalance implant, the highly stressed volume was located in the middle of the implant, but on the left side.

Position 2 - Fig. 7: As in position 1, the maximal von-Mises equivalent stress occurred, for the Contour Lock and the two TomoFix plates, at the corner on the right side. The margin of the middle region of the PEEKPower plate below the proximal hole above the wedge was the hot spot. The maximal stresses were located at the proximal part of the four other implants and in the middle region of the iBalance implant.

Position 3 - Fig. 8: In position 3, the maximal equivalent stresses were located for the TomoFix sm and the PEEKPower plates in the margin of the middle region above the first distal hole. For the TomoFix std., the region of maximal stress was located on the right. The stress distribution in the cross section was similar to that of position 2. Stresses were additionally concentrated above the first distal hole. For the iBalance, the most stressed volume was located in the middle of the centre of the implant.

\section{Maximal stress values in the implants}

Table 4 gives a comparative summary of the maximal equivalent stresses $\left(\sigma_{e q, \max }\right)$ in the implants and the threshold values of the materials. All the equivalent 


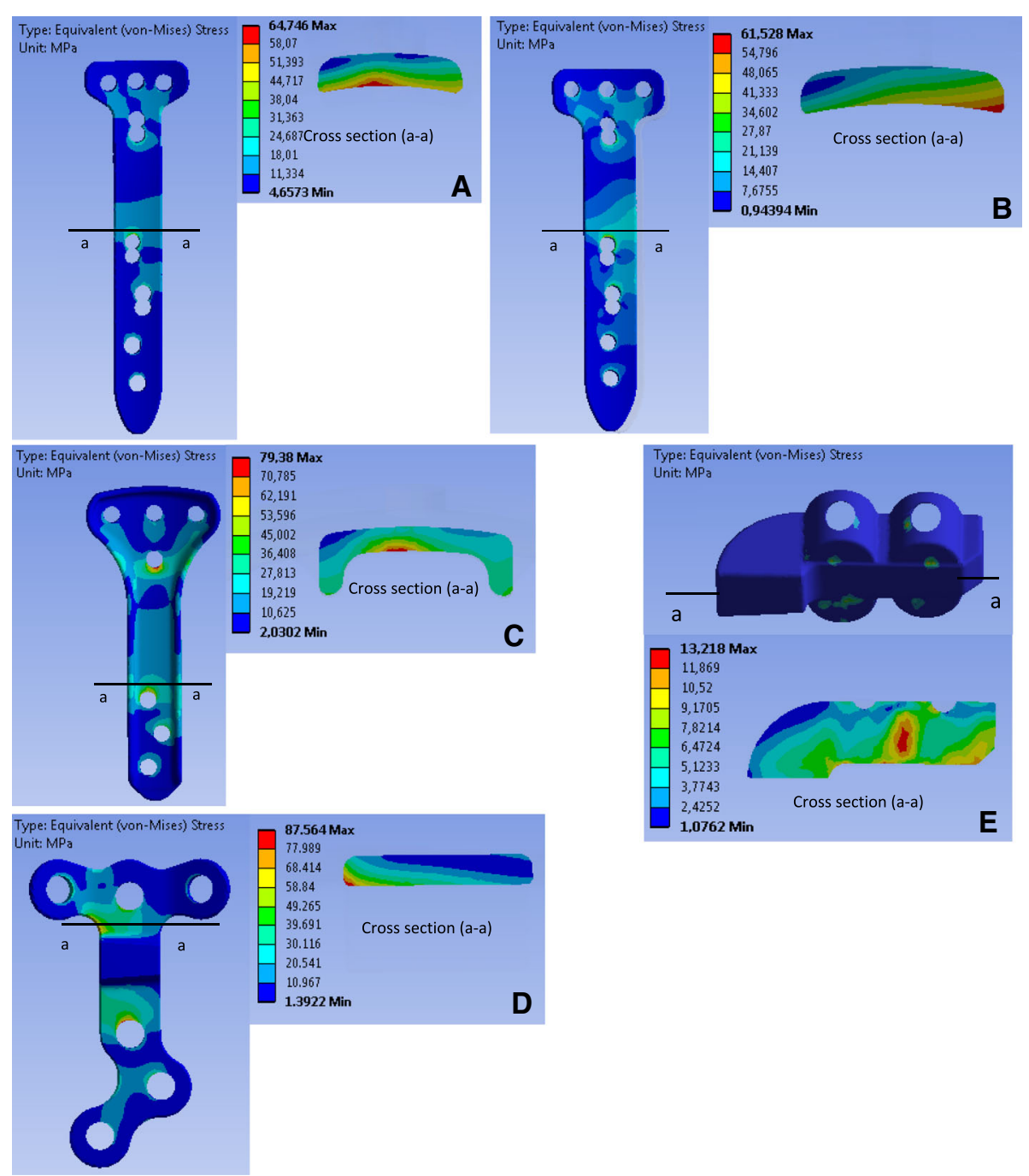

Fig. 8 Equivalent stress (von-Mises) in the implants in position 3: The letters $\mathbf{a}, \mathbf{b}, \mathbf{c}, \mathbf{d}$ and $\mathbf{e}$ indicate the TomoFix sm, the TomoFix std., the PEEK Power, the Contour Lock and the iBalance implants

stresses in the implants were smaller than the yield stress $R_{e}$, the ultimate strength $R_{m}$ and the fatigue limit $\sigma_{D}$.

By taking the yield strength $R_{e}$ as the reference threshold, all the implants showed safety factors higher than or equal to 1.4, independent to the load applied. The smallest safety factor (1.4) was obtained for the TomoFix sm in the case of the simplified loading, and the highest safety factor (18.4) was obtained for the iBalance implant at position 2 .

Table 4 Comparative summary of the maximal equivalent von-Mises stresses in the implants and the corresponding material strength values

\begin{tabular}{|c|c|c|c|c|c|c|c|}
\hline \multirow[t]{3}{*}{ Implants } & \multicolumn{4}{|c|}{$\sigma_{e q, \max }(\mathrm{MPa})$} & \multirow[t]{3}{*}{$R_{e}(\mathrm{MPa})$} & \multirow[t]{3}{*}{$R_{m}(\mathrm{MPa})$} & \multirow[t]{3}{*}{$\overline{\sigma_{D}(\mathrm{MPa})}$} \\
\hline & \multirow{2}{*}{$\begin{array}{l}\text { Simplified } \\
\text { loading }\end{array}$} & \multicolumn{3}{|c|}{ Muscle actions } & & & \\
\hline & & Position 1 & Position 2 & Position 3 & & & \\
\hline Contour Lock & 157 & 144 & 31 & 88 & 250 & 500 & 200 \\
\hline TomoFix sm & 174 & 109 & 51 & 65 & 250 & 500 & 200 \\
\hline iBalance & 12 & 8 & 5 & 13 & 92 & $(92-100)$ & 70 \\
\hline PEEKPower & 89 & 48 & 42 & 79 & 177.5 & 210 & 160 \\
\hline TomoFix std & 134 & 100 & 49 & 62 & 250 & 500 & 200 \\
\hline
\end{tabular}


Table 5 Tensile $(T)$ and compressive $(C)$ stresses in the cross sections of maximum von-Mises stress in the implants

\begin{tabular}{|c|c|c|c|c|c|c|c|c|}
\hline \multirow[t]{3}{*}{ Implants } & \multirow{2}{*}{\multicolumn{2}{|c|}{ Simplified loading }} & \multicolumn{6}{|c|}{ Muscle actions } \\
\hline & & & \multicolumn{2}{|c|}{ Position 1} & \multicolumn{2}{|c|}{ Position 2} & \multicolumn{2}{|c|}{ Position 3} \\
\hline & $\mathrm{T}(\mathrm{MPa})$ & $\mathrm{C}(\mathrm{MPa})$ & $\mathrm{T}(\mathrm{MPa})$ & $\mathrm{C}(\mathrm{MPa})$ & $\mathrm{T}(\mathrm{MPa})$ & $\mathrm{C}(\mathrm{MPa})$ & $\mathrm{T}(\mathrm{MPa})$ & $\mathrm{C}(\mathrm{MPa})$ \\
\hline Contour Lock & 108 & -156 & 81 & -137 & 58 & -60 & 16 & -47 \\
\hline TomoFix sm & 83 & -174 & 51 & -110 & 2 & -50 & 18 & -68 \\
\hline iBalance & 1 & -12 & 7 & -8 & 2 & -4 & 4 & -11 \\
\hline PEEKPower & 9 & -89 & 24 & -46 & 16 & -13 & 16 & -86 \\
\hline TomoFix std & 53 & -134 & 41 & -82 & 9 & -46 & 15 & -62 \\
\hline
\end{tabular}

\section{Predominant types of stresses in the implants}

The implants were predominantly subjected to bending. The tensile $(\mathrm{T})$ and compressive $(\mathrm{C})$ stresses values in the cross sections of maximum equivalent stress in the implants are reported in Table 5.

The maximal von-Mises stresses were predominantly compressive stresses. The maximal tensile stresses were obtained when the lower limb was in position 1 under muscle actions.

\section{Stress distributions in the contralateral cortex}

Higher stresses in the tibia were located in the contralateral cortical bone. Figure 9 shows the distribution of the equivalent von-Mises stress in the cross section of the contralateral cortex (Fig. 2-b). The stress distribution altered almost uniformly from the lateral to the medial side in the case of the simplified loading (Fig. 9-I). This was not the case for the other loading variations including the muscle forces (Fig. 9-II to IV). The maximal stresses were located in the area at the tip of the open wedge on the anterior and posterior corners of the cross section. Beyond the tip of the open wedge and the corners, the stresses were smaller than $50 \mathrm{MPa}$ (Fig. 9-I to III), except in the case of position 4 (Fig. 9-IV), where they were smaller than $70 \mathrm{MPa}$. The stresses in the contralateral cortex decreased rapidly from the hot spot to the minimal stresses (Fig. 10). The iBalance implant offered the best support to the contralateral cortex whereas the PEEKPower offered the least, regardless of the considered loading.

Based on the stress analysis along the chosen path B1B2 (Fig. 2-b) in the case of the simplified loading (Fig. 10-a), the Contour Lock plate appeared to relieve the contralateral cortex of high stresses better than the TomoFix plates. In position 1 , the TomoFix std. was inferior to the iBalance, the Contour Lock and the TomoFix sm regarding that property. In position 2 and 3, apart from the PEEKPower and the iBalance, the other plates were approximately equivalent.

\section{Micromovements of the wedge}

Figure 11 shows the micromovements captured by means of the three weak springs ( $A B, C D$ and $E F)$ that were attached between the outermost distal and proximal borders of the wedge on the medial side. The behaviours of the wedge were qualitatively identical under the simplified loading, and under the muscle force loading in position 1 (Fig. 11-a and b). The Pearson's value was $r=0.982$. This identical comportment corresponded to a posterior closing and an anterior opening of the wedge. In the previously mentioned comportment, the closing and the opening of the wedge were consistent with a compression and a distraction respectively. There was no other identical deformation pattern of the wedge between the other loading variations. In position 3, for all implants except for the Contour Lock, the wedge exhibited an anterior closing and a posterior opening, although, the latter still resulted in compression of the wedge (Fig. 11-d). The highest micromovements under muscle forces were obtained in position 3 (235 $\mu \mathrm{m}$ for the PEEKPower plate). Generally, the iBalance implant showed the smallest micromovements ( $7 \mu \mathrm{m}$ in average), when the muscles forces were included.

\section{Discussion}

The key finding of the present study is that perpendicularly applying a vertical load to the tibia plateau is qualitatively equivalent to the realistic loading of the tibia including muscle forces in position 1 of the stance phase. The position 1 corresponded to $15 \%$ of gait cycle with $22^{\circ}$ knee flexion. The stresses in all the implants were smaller than the yield stress, the ultimate strength and the fatigue limit of the respective material. This last observation means that the implants will not fail due to fatigue in the modelled biomechanical environment under physiological loading during normal walking. The PEEKPower implant exhibited the highest micromovements of the wedge, whereas the iBalance exhibited the smallest.

Two loading types were considered in the present FE analysis study; the first type consisted of a vertical load being applied perpendicularly on the tibia head. The second loading type consisted of three loading variations of the tibia, including the muscle forces, in three positions 
Type: Equivalent (von-Mises) Stress Unit: MPa

(I)
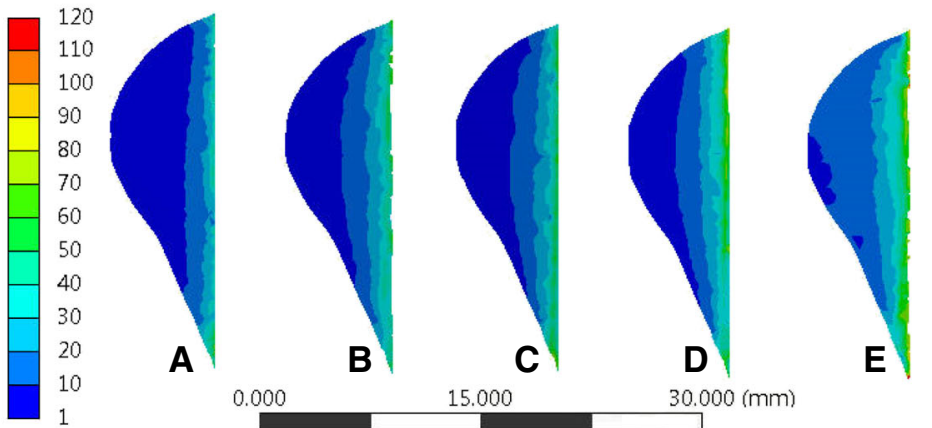

A 0.000

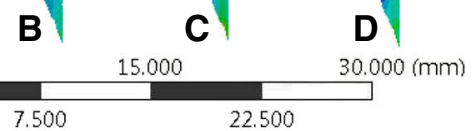

E

(II)
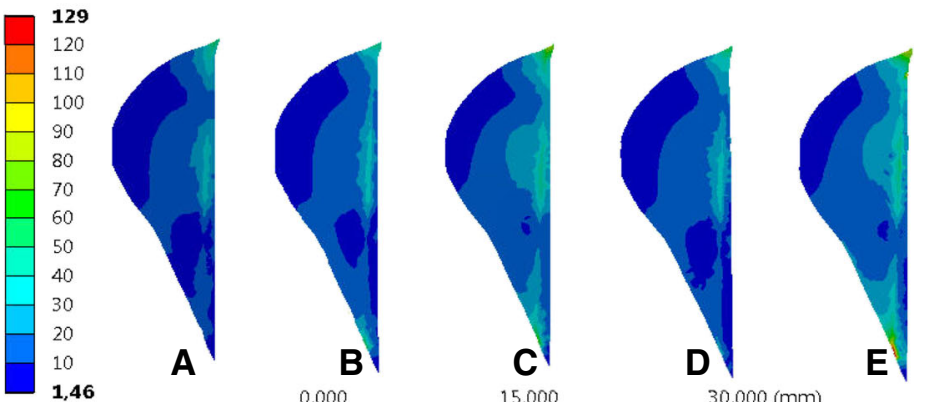

(III)
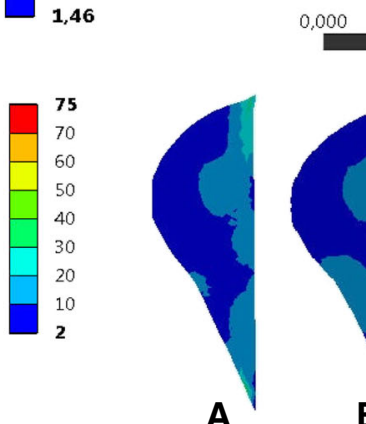
$30,000(\mathrm{~mm})$

E
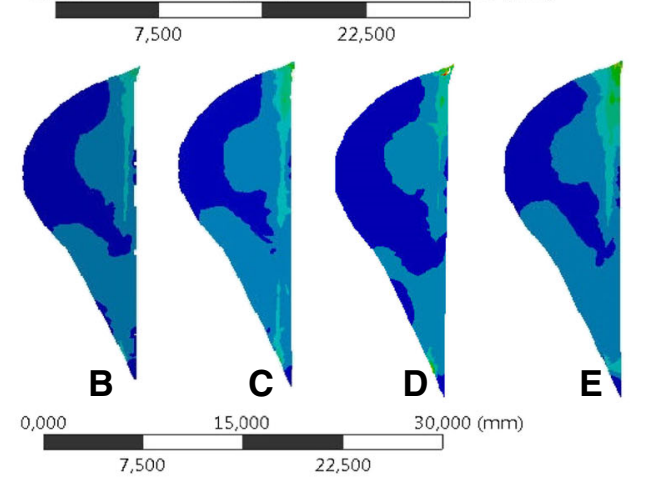

(IV)
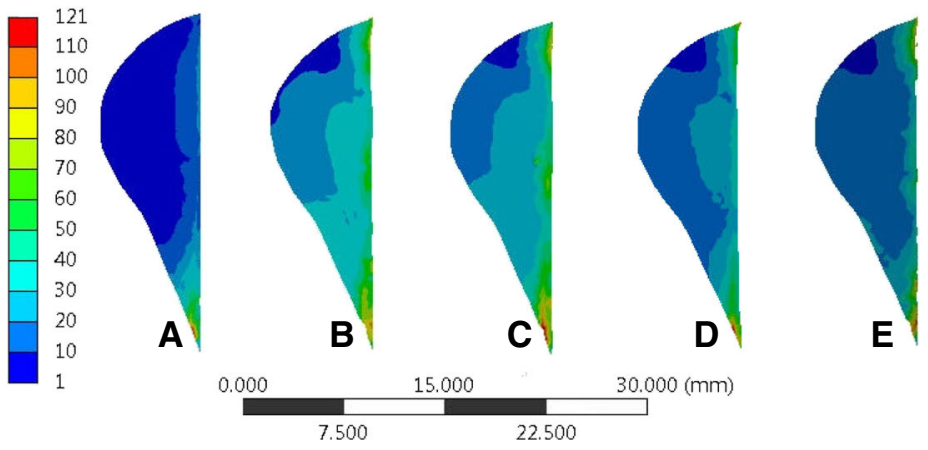

Fig. 9 Equivalent (von-Mises) stress in the contralateral cortex: (I) simplified loading of the tibia head. (II) Lower limb with muscle force loading in position 1. (III) Lower limb with muscle force loading in position 2. (IV) Lower limb with muscle force loading in position 3. The letters a, b, c, d and $\mathbf{e}$ indicate the iBalance, the TomoFix sm, the TomoFix std., the Contour Lock and the PEEKPower implants

of the lower limb in the stance phase. The loading in the first position appeared to be similar to an axial load perpendicular to the tibia plateau. On the other hand, the loading of the lower limb in the other two positions led to different observations compared to the simple vertical loading. This emphasises the necessity to improve the experimental testing by incorporating other forces and creating comparable multiaxial loading of the 


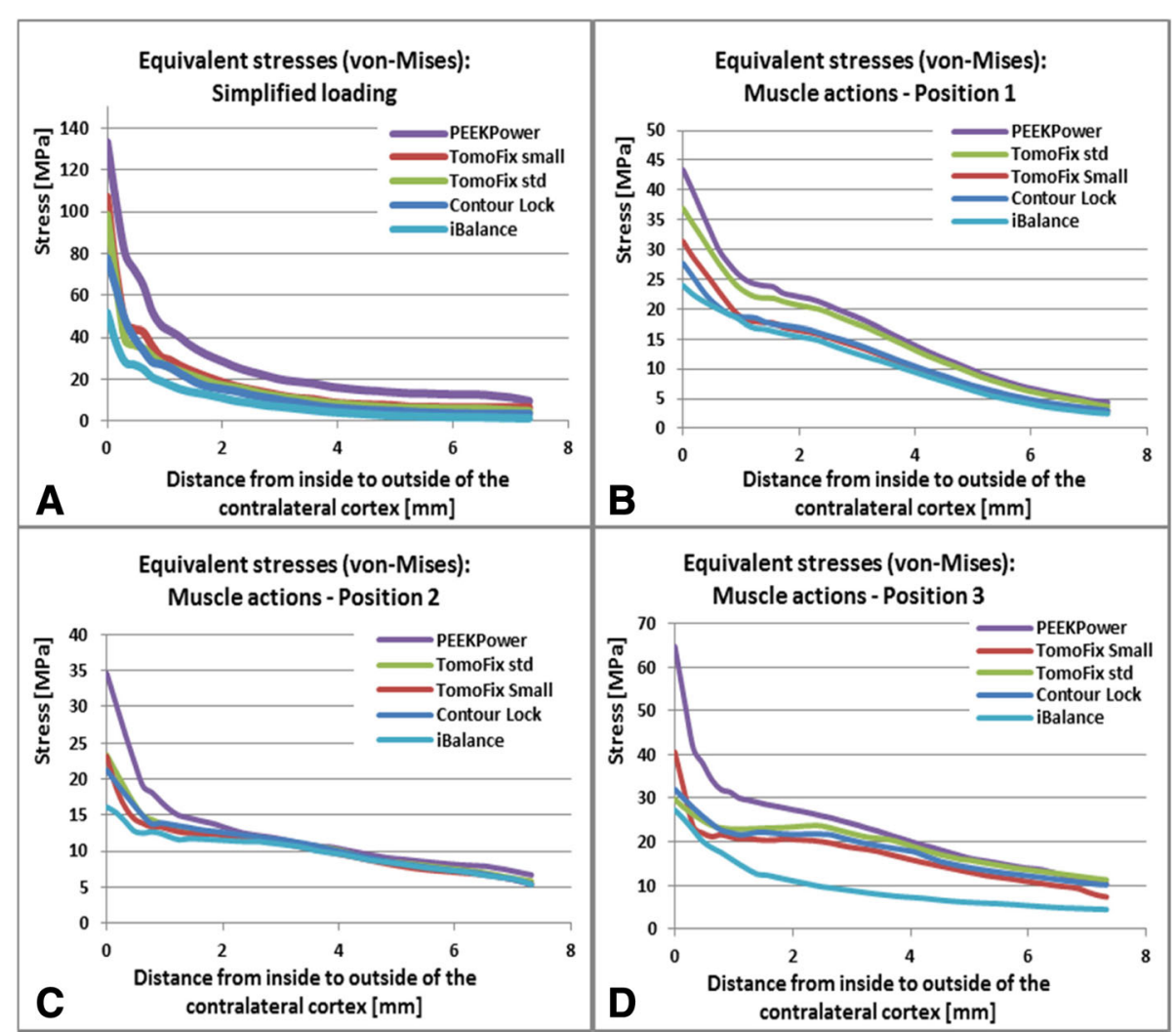

Fig. 10 Equivalent stresses along the path B1B2 of the contralateral cortex (Fig. 2-b): a simplified loading of the tibia head. b Lower limb under muscle force loading in the position 1. c Lower limb under muscle force loading in the position 2. d Lower limb under muscle force loading in the position 3

osteotomized tibia. We did not find any other study analysing the MOWHTO by means of FE analysis, which includes detailed muscle forces.

As reported in Table 5, the stress concentrations predominantly consisted of compressive stresses. The stress concentrations in all the implants were smaller than the tensile strength values of the respective materials, as already mentioned. However, it should be noted that the mechanical properties of the material used in the present study result from tensile tests, and are normally smaller than compressive strength values i.e. the safety is even higher. Except for the iBalance implant, the highest equivalent stresses in the implants resulted from the simplified loading and not from the realistic loading, which included the muscle forces. The preceding observation corresponds to the fact that the section forces in the cross section passing through the middle of the wedge (Fig. 2-c, Table 2) were higher for the simplified loading than for the muscle force loading. Although the section force at the level of the transepicondylar axis corresponded to the knee contact forces from the validated MRB model. This means that the combined action of the muscle forces and the GRF on the tibia plateau is not the same at different locations of the tibia. Hence, applying the peak values of the knee joint contact forces to the tibia plateau in FE analysis including the tibia, as it is commonly performed in the literature (Blecha et al. 2005; Izaham et al. 2012; Luo et al. 2015; Huang et al. 2015), and as it was done for the simplified loading in the present study, overloads the tibia compared to a more realistic loading including the muscle forces.

The stress concentrations in the TomoFix sm and in the TomoFix std. were located at the same part of the plate, but were higher for the TomoFix sm. This is correlated to the fact that the two TomoFix plates have the same design and the TomoFix sm is smaller than the TomoFix std. and was designed for small stature patients. The fact that the stresses were the smallest in the iBalance implant for all the loading variations considered, can be attributed to the fact that this implant has the largest cross section.

The equivalent von-Mises stresses in the contralateral cortex were higher at the tip of the wedge compared to its values in the external side (Fig. 9). For all implant, regardless of the loading considered, the stress concentration on the cross section of the contralateral cortex was smaller than the ultimate stresses of the cortical bone, which were reported to be $163 \mathrm{MPa}$ and $183 \mathrm{MPa}$ in axial tension and compression respectively, by Burstein et al. (Burstein et al. 1976). The iBalance allowed the 


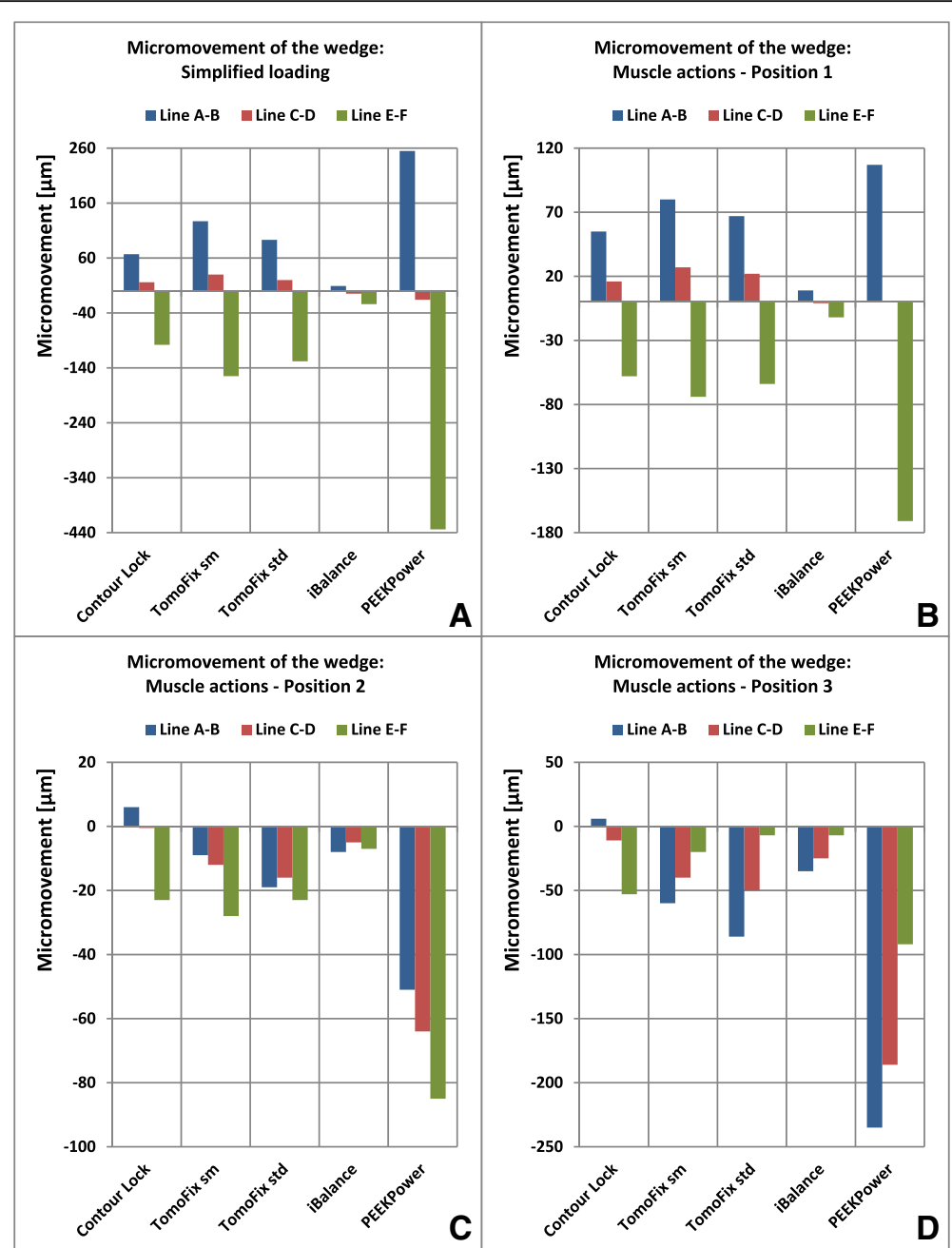

Fig. 11 Micromovements of the open wedge: The micromovements under the simplified loading and the muscle force loading in position 1 were correlated

largest portion of the cross section with stresses lower than $10 \mathrm{MPa}$ and the PEEKPower the smallest. The stress evolution along the chosen path B1B2 (Fig. 2-b) in the case of the simplified loading (Fig. 10-a) led to a similar ranking of the fixation devices as in our previously performed biomechanical experimental study (Diffo Kaze et al. 2015). There we reported that the Contour Lock had the highest mechanical stability followed by the iBalance, the TomoFix std., the TomoFix sm and the PEEKPower. This ranking suggests that the finite element models and the experimental setting were in good agreement.

Micromovements of the wedge were quite small for the iBalance and the Contour Lock implants. This observation is in good agreement with the results of our biomechanical experimental study (Diffo Kaze et al. 2015), where we compared the static and fatigue strength of the implants considered in the present study. Röderer et al. reported results that linked low bone formation underneath locking plates to high implant stiffness in locking plating (Röderer et al. 2014). Therefore, the advantage of the higher mechanical stability provided by the implants iBalance and Contour Lock, in comparison to the PEEKPower and the TomoFix plates, could be called into question. Minimum mechanical stability is a necessary but not sufficient condition for bone formation; there are other aspects that need to be considered (Schröter et al. 2015). We did not find clinical postoperative studies of MOWHTO with the iBalance and Contour Lock implants. Numerous clinical postoperative studies reported good outcomes of MOWHTO in term of stable correction, early full weight bearing and bone union for TomoFix plates (Takeuchi et al. 2009; Brinkman et al. 2010; Brosset et al. 2011, Schröter et al. 2017). Cotic et al. reported that the second generation PEEK Power plate was safe for MOWHTO, although there was one case of non-union out of 28 patients (Cotic et al. 2015). 
Luo et al. reported micromovements of the wedge, $420 \mu \mathrm{m}$ opening versus $926 \mu \mathrm{m}$ closing, with a TomoFix plate (Luo et al. 2015). However, trabecular bone was considered in their model and the axial load that was applied on the tibia plateau was asymmetrical with a distribution of $40 \%$ on the lateral side. The micromovements were very small and the differences observed between the present study and the study by Luo et al. can also be related to differences in Young's moduli used for the plates. Luo et al. did not indicate which value they used.

In a clinical point of view, the implants iBalance and Contour Lock should be used if a rigid bone-implant construct is required. Flexible bone-implant constructs will be obtained with the TomoFix and PEEKPower plates. However, one should proceed with caution while transferring the results of the present study to clinical settings, because the present study has some limitations. An obvious limitation is the absence of trabecular bone in the modelling of the tibia. The trabecular bone was not considered in order to avoid the modelling of the interface cortical bone-trabecular bone, which is not a well-defined limit. Furthermore, the contact interfaces were modelled as bonded. The jaw compressive force induced by the remaining intact opposite cortex, medial collateral and patellar ligament, which attempt to close the wedge after opening by the surgeon (Blecha et al. 2005), was not considered. The modelled osteotomized tibia corresponded to a state directly after the osteotomy without onset of ossification. The muscle forces that were included in the study were calculated by means of kinetics and kinematics data obtained from an asymptomatic healthy individual. Full weight bearing is not prescribed until at least two weeks after surgery, but was considered in the present study.

\section{Conclusion}

An axial compressive load applied perpendicularly to the tibia plateau, with a magnitude equal to the first peak value of the knee joint contact forces, corresponds quite well to a realistic loading of the tibia during the stance phase of normal gait (at 15\% of gait cycle and a knee flexion of about 22 degrees). However, this magnitude of the knee joint contact forces overloads the tibia compared to more realistic calculations, where the muscle forces are considered. The iBalance and Contour Lock implants provide higher rigidity to the bone-implant constructs compared to the TomoFix and the PEEK Power plates.

\section{Abbreviations}

3D: Three-dimensional; BW: body weight; COP: centre of pressure; DOF: degrees of freedom; FE: finite element; GRF: ground reaction forces; MOWHTO: Medial open wedge high tibial osteotomy; MRB: musculoskeletal rigid body; MRI: magnetic resonance imaging; PEEK: polyetheretherketone; sm: Small stature; std: Standard

\section{Authors' contributions}

All authors have contributed to writing and correcting this manuscript. ADK: Principal author, Building the geometry, finite element modelling, analysing results and writing the manuscript. SM: analysing results and writing the manuscript. SK: Finite element modelling and writing the manuscript. JB: writing the manuscript. AH: writing the manuscript. CW: Building the geometry and writing the manuscript. AH: Writing the manuscript. DP: analysing results

and writing the manuscript. All authors read and approved the final manuscript.

\section{Competing of interests}

The authors declare that they have no competing interests.

\section{Publisher's Note}

Springer Nature remains neutral with regard to jurisdictional claims in published maps and institutional affiliations.

\section{Author details}

${ }^{1}$ Faculty of Science, Technology and Communication, University of Luxembourg, 6, rue R. Coudenhove-Kalergi, L-1359 Luxembourg, Luxembourg. ${ }^{2}$ Department of Orthopedic Surgery, Centre Hospitalier de Luxembourg, L-1460 Luxembourg, Luxembourg. ${ }^{3}$ Luxembourg Institute of Health, Luxembourg L-1445, Luxembourg. ${ }^{4}$ Cartilage Net of the Greater Region, 66421 Homburg, Germany. ${ }^{5}$ University of Winchester \& Basingstoke and North Hampshire Hospital, Sparkford Road, Winchester SO22 4NR Hampshire, England. 'Saarland University Medical Center, Kirrberger Str., Homburg 66421 Homburg, Germany.

Received: 6 November 2017 Accepted: 26 July 2018

Published online: 08 August 2018

\section{References}

Advanced Industrial (2015) PEEK CA30 Polyetheretherketon, 30\% carbon fiber reinforced. http://www.cncplastics.com/pdf/ PEEK\%20450G\%20DATA\%20SHEET.pdf. Accessed 15 Jan 2015

Agneskirchner J, Freiling D, Hurschler C, Lobenhoffer P (2006) Primary stability of four different implants for opening wedge high tibial osteotomy. Knee Surg Sports Traumatol Arthrosc 14:291-300

AnyBody Technology (2014) Model repository (AMMR). http://www.anybody.aau. dk/Repository. Accessed 25 Jan 2014

Asfour S, Eltoukhy M (2011) Development and validation of a three-dimensional biomechanical model of the lower extremity. In: Klika V (ed) Theoretical Biomechanics. InTech. https://doi.org/10.5772/24156

Beillas P, Begeman P, Yang K, King A, Arnoux P-J, Kang H-S et al (2001) Lower limb: advanced FE model and new experimental data. Stapp Car Crash J 45: 469-494

Bergmann GC (2008). Orthoload. https://orthoload.com/. Accessed 12 Mar 2015. Blecha LD, Zambelli PY, Ramaniraka NA, Bourban PP, Manson JA, Pioletti DP (2005) How plate positioning impacts the biomechanics of the open wedge tibial osteotomy; a finite element analysis. Comput Meth Biomech Biomed Eng 8(5):307-313

Brinkman JM, Hurschler C, Agneskirchner J, Lobenhoffer P, Castelein R, van Heerwaarden R (2014) Biomechanical testing of distal femur osteotomy plate fixation techniques: the role of simulated physiological loading. J Exp Orthop 1(1). https://doi.org/10.1186/s40634-014-0001-1

Brinkman JM, Luites J, Wymenga A, van Heerwaarden R (2010) Early full weight bearing is safe in open-wedge high tibial osteotomy: RSA analysis of postoperative stability compared to delayed weight bearing. Acta Orthop 81: 193-198

Brosset T, Pasquier G, Migaud H, Gougeon F (2011) Opening wedge high tibial osteotomy performed without filling the defect but with locking plate fixation (TomoFix ${ }^{T M}$ ) and early weight-bearing: prospective evaluation of bone union, precision and maintenance of correction in 51 cases. Orthop Traumatol Surg Res 97:705-711

Burstein A, Reilly D, Martens M (1976) Aging of bone tissue: mechanical properties. J Bone Joint Surg Am 58(1):82-86

Claes $L E$, Augat P, Suger G, Wilke H (1997) Influence of size and stability of the osteotomy gap on the success of fracture healing. J Orthop Res 15(4):577-584

Claes LE, Heigele CA (1999) Magnitudes of local stress and strain along bony surfaces predict the course and type of fracture healing. J Biomech 32:255-266

Claes LE, Heigele CA, Neidlinger-WIIke C, Kaspar D, Seidl W, Margevicius KJ, Augat $P$ (1998) Effects of mechanical factors on the fracture healing process. Clin Orthop Relat 355(Suppl):132-134 
Cotic M, Vogt S, Feucht M, Saier T, Minzlaff P, Hinterwimmer S, Imhof A (2015) Prospective evaluation of a new plate fixator for valgus-producing medial open-wedge high tibial ost.Eotomy. Knee Surg Sports Traumatol Arthrosc 23(12):3707-3716

DeFrate L, Nha K, Papannagari R, Moses J, Gill T, Li G (2007) The biomechanical function of the patellar tendon during in-vivo weight-bearing flexion. $J$ Biomech 40(8):1716-1722

Diffo Kaze A, Maas S, Arnoux P-J, Wolf C, Pape D (2017) A finite element model of the lower limb during stance phase of gait cycle including the muscle forces Biomed Eng Online, 16: https://doi.org/10.1186/s12938-017-0428-6

Diffo Kaze A, Maas S, Waldmann D, Zilian A, Dueck K, Pape D (2015) Biomechanical properties of five different currently used implants for openwedge high tibial osteotomy. J Exp Orthop 2(14). https://doi.org/10.1186/ s40634-015-0030-4

Donahue T, Hull M, Rashid M, Jacobs C (2002) A finite element model of the human knee joint for the study of Tibio-femoral contact. J Biomech Eng 124: $273-280$

Evans F (1976) Mechanical properties and histology of cortical bone from younger and older men. Anat Rec 185(1):1-11

Farrokhi S, Keyack J, Powers C (2011) Individuals with patellofemoral pain exhibit greater patellofemoral joint stress: a finite element analysis study. Osteoarthr Cartil 19(3):287-294

Fischer U, Heizler M, Näher F, Paetzold H, Gomering R, Kilgus R et al (2011) Tabellenbuch Metall. Verlag Europa Lehrmittel, Paderborn

Garcia-Gonzalez A, Rusinek A, Jankowiak T, Arias A (2015) Mechanical impact behavior of polyether-ether-ketone (PEEK). Compos Struct 124:88-99

Hansen P, Bojsen-Moller, Aagaard P, Kjaer P, Magnusson S (2006) Mechanical properties of the human patellar tendon, in vivo. Clin Biomech 21(1):54-58

Hao Z, Jin D, Zhang Y, Zhang J (2007) A Finite 3D Model of in Vivo Human Knee Joint Based on MRI for the Tibiofemoral Joint Contact Analysis. In: Duffy V (ed) Digital Human Modeling. ICDHM 2007. Lecture notes in computer Science. Springer, Berlin

Haraldsson B, Aagaard P, Krogsgaard M, Alkjaer T, Kjaer M, Magnusson S (2005) Region-specific mechanical properties of the human patella tendon. J Appl Physiol 98(3):1006-1012

Heinlein B, Kutzner I, Graichen F, Bender A, Rohlmann A, Halder AM, Beier A, Bergmann G (2009) ESB clinical biomechanics award 2008: complete data of total knee replacement loading for level walking and stair climbing measured in vivo with a follow-up of 6-101 months. Clin biomech (Bristol, Avon) 24:315-326

Huang X, Zhi Z, Yu B, Chen F (2015) Stress and stability of plate-screw fixation and screw fixation in the treatment of Schatzker type IV medial tibial plateau fracture: a comparative finite element study. J Orthop Surg Res 182(10). https://doi.org/10.1186/s13018-015-0325-2

Izaham R, Kadir MR, Rashid AH, Hossain G, Kamarul T (2012) Finite element analysis of Puddu and Tomofix plate fixation for open wedge high tibial osteotomy. Injury 43:898-902

Kiapour A, Kiapour A, Kaul V, Quatman C, Wordeman S, Hewett T, Demetropoulos CK, Goel V (2014) Finite element model of the knee for investigation of injury mechanisms: development and validation. J Biomech Eng 136:1. https://doi. org/10.1115/1.4025692

Klein P, Schell H, Streitparth F, Heller M, Kassi JP, Kandziora F, Bragulla H, Haas NP, Duda GD (2003) The initial phase of fracture healing is specifically sensitive to mechanical conditions. J Orthop Res 21:662-669

Kohn DH, Ducheyne P (2005) Materials for bone and joint replacement. In: Cahn RW, Haasen P, Kramer EJ (eds) Materials science and technology: a comprehensive treatment. WILEY-VCH verlag GmbH \& Co. KGaA, Weinheim

Kutzner I, Heinlein B, Graichen F, Bender A, Rohlmann A, Halder A, Beier A, Bergmann $G$ (2010) Loading of the knee joint during activities of daily living measured in vivo in five subjects. J Biomech 43:2164-2173

Victrex Ltd (2015) Material Properties Guide. https://www.victrex.com/ /media/ literature/en/victrex_properties-guide_en_metric.pdf. Accessed 12 July 2015

Luo CA, Hua SY, Lin SC, Chen CM, Tseng CS (2013) Stress and stability comparison between different systems for high tibial osteotomies. BMC Musculoskelet Disord 14:110. https://doi.org/10.1186/1471-2474-14-110

Luo CA, Hua SY, Lin SC, Chen CM, Tseng CS (2015) Placement-induced effects on high tibial osteotomized construct - biomechanical tests and finite-element analyses. BMC Musculoskelet Disord 16:235. https://doi.org/10.1186/s12891015-0630-2

Maas S, Diffo Kaze A, Dueck K, Pape D (2013) Static and Dynamic Differences in Fixation Stability between a Spacer Plate and a Small Stature plate fixator used for high Tibial osteotomies: a biomechanical bone composite study. ISRN Orthop 2013. https://doi.org/10.1155/2013/387620

MakeltFrom.com (2015) Unfilled PEEK. http://www.makeitfrom.com/materialproperties/Unfilled-PEEK. Accessed 22 Jan 2015

Manders C, New A, Rasmussen J (2008) Validation of musculoskeletal gait simulation for use in investigation of Total hip replacement. The 16th congress od the European Society of Biomechanics, Lucerne

Pape D, Seil R, Adam F, Kohn D, Lobenhoffer P (2004) Bildgebung und präoperative Planung der Tibiakopfosteotomie. Orthopäde 33:122-134

Pauchard Y, Ivanov TG, McErlain DD, Milner JS, Giffin JR, Birmingham TB, Holdsworth DW (2015) Assessing the local mechanical environment in medial opening wedge high Tibial osteotomy using finite element analysis. J Biomech Eng 137(3). https://doi.org/10.1115/1.4028966

Peña E, Calvo B, Martinez M, Palanca D, Doblaré M (2005) Finite element analysis of the effect of meniscal tears and meniscectomies on human knee biomechanics. Clin Biomech (Bristol, Avon) 20(5):498-507

Röderer G, Gebhard F, Duerselen L, Ignatius A, Claes L (2014) Delayed bone healing following high tibial osteotomy related to increased implant stiffness in locked plating. Injury 45(10):1648-1652

Schröter S, Ateschrang A, Löwe W, Nakayama H, Stöckle U, Ihle C (2017) Early full weight-bearing versus 6-week partial weight-bearing after open wedge high tibial osteotomy leads to earlier improvement of the clinical results: a prospective, randomised evaluation. Knee Surg Sports Traumatol Arthrosc 25(1):325-332

Schröter S, Freude T, Kopp MM, Konstantinidis L, Döbele S, Stöckle U, van Heerwaarden R (2015) Smoking and unstable hinge fractures cause delayed gap filling irrespective of early weight bearing after open wedge osteotomy. Arthroscopy 31(2):254-265

Spahn G, Mückley T, Kahl E, Klinger HM, Steinhauser E, Hofmann GO (2007) Biomechanical investigation of uniplanar and biplanar cuts in openingwedge high tibial osteotomy. B/Omaterialien 8(2):71-75. https://doi.org/10. 1515/BIOMAT.2007.8.2.71

Spahn G, Wittig R (2002) Primary stability of various implants in tibial opening wedge osteotomy: a biomechanical study. J Orthop Sci 7(6):683-687

Stoffel K, Stachowiak G, Markus K (2004) Open wedge high tibial osteotomy: biomecanical investigation of the modified Arthrex osteotomy plate (Puddu plate) and the TomoFix plate. Clin Biomech 1:944-950

Takeuchi R, Ishikawa H, Aratake M, Bito H, Saito I, Kumagai K, Akamatsu Y, Saito T (2009) Medial opening wedge high tibial osteotomy with early full weight bearing. Arthrosc 25(1):46-53

Thielen T (2009) Optimierung der Tragfähigkeit von antibiotikabeladenen PMMA Hüftinterimsprothesen. University of Luxembourg. SHAKER VERLAG, Aachen

Watanabe K, Kamiya T, Suzuki D, Otsubo H, Teramoto A, Suzuki T, Yamashita T (2014) Biomechanical stability of open-wedge high tibial osteotomy: comparison of two locking plates. Open J Orthop 4:257-262

Yamaji T, Ando K, Wolf S, Augat P, Claes L (2001) The effect of micromovement on callus formation. J Orthop Sci 6(6):571-575. https://doi.org/10.1007/ s007760100014

Zhim F, Laflamme GY, Viens H, Saidane K, Yahia L (2005) Biomechanical stability of high tibial opening wedge osteotomy: internal fixation versus external fixation. Clin Biomech 20:871-876

\section{Submit your manuscript to a SpringerOpen ${ }^{\circ}$ journal and benefit from:}

- Convenient online submission

- Rigorous peer review

- Open access: articles freely available online

High visibility within the field

Retaining the copyright to your article

Submit your next manuscript at $>$ springeropen.com 